\title{
Manajemen Pengendalian Hama Ulat Pemakan Daun Kelapa Sawit (UPDKS) di Desa Jambuk Kecamatan Bongan, Kabupaten Kutai Barat, Provinsi Kalimantan Timur
}

\author{
Pest Control Management of Palm Oil Leaf-Eating Caterpillars at Jambuk Village, \\ Bongan District, Kutai Barat Regency, East Kalimantan Province \\ Munawir Haris, Jamaluddin*, jumri \\ Politeknik Pertanian Negeri Samarinda, Jl. Samratulangi, Samarinda, Indonesia. \\ *Corresponding Author: jamaluddin8871@gmail.com
}

\begin{abstract}
Abstrak
Penelitian ini bertujuan untuk mengetahui manajemen pengendalian hama Ulat Pemakan Daun Kelapa Sawit (UPDKS) di PT. Farinda Bersaudara, Desa Jambuk, Kecamatan Bongan, Kabupaten Kutai Barat, Provinsi Kalimantan Barat. Data diperoleh melalui observasi, peninjauan lapangan dan dokumentasi. Hasil penelitian menunjukkan bahwa manajemen pengendalian Hama Ulat Pemakan daun (UPDKS) yang dilakukan di PT. Farinda Bersaudara telah sesuai dengan apa yang diharapkan yaitu dapat megurangi populasi hama pada estate Penawai sebesar $90 \%$. Selain itu, pengendalian hama dapat meningkatkan hasil produksi sebesar $4 \%$ dilihat dari data produksi tahun 2019 yaitu $88 \%$ dan setelah dilakukannya pengendlian produksi tahun 2020 menjadi $92 \%$.
\end{abstract}

Kata kunci : Manajemen pengendalian Hama, Ulat Pemakan Daun Kelapa sawit, Injeksi batang,

\section{Abstract}

This study aims to determine the control management of oil palm leaf-eating caterpillar pests (OPLCP) At PT. Farinda Brothers, Jambuk Village, Bongan District, West Kutai Regency, West Kalimantan Province. Data obtained through observation, field, documentation. The results showed that the leaf-eating caterpillar pest control management (OPLCP) was carried out at PT. Farinda Brothers has met what was expected, which is to reduce the pest population in the Penawai estate by $90 \%$. In addition, pest control can increase production yields by 4\%, seen from production data in 2019 which is $88 \%$ and after controlling production in 2020 it becomes $92 \%$.

Keywords: Pest control management, oil palm leaf-eating caterpillars, stem injection

\section{PENDAHULUAN}

Masalah hama kelapa sawit akhir-akhir ini cenderung meningkat dan beragam. Tingkat serangan hama khususnya hama ulat pemakan daun kelapa sawit (UPDKS) tidak sama antar daerah. Serangan UPDKS menyebab kan kelapa sawit kehilangan daun dan akhirnya secara signifikan akan menurunkan produksi kelapa sawit.

Indonesia merupakan salah satu Negara yang memiliki potensi untuk penanaman investasi perkebunan kelapa sawit, karena memiliki berbagai keunggulan.indonesia memiliki kesesuaian lahan yang dikehendaki oleh tanaman kelapa sawit terbentang mulai wilayah timur hingga barat Indonesia. Indonesia memlliki lahan potensial untuk kelapa sawit mencapai 26,5 juta hektar yang tersebar berbagai provinsi di Indonesia.

Perkembangan ini diikuti juga dengan perubahan hama penyakit seiring dengan pertambahan generasi tanam. Masalah hama, penyakit dan gulma yang dihadapi 25 tahun yang lalu berbeda dengan masalah hama, penyakit dan gulma saat ini. Hama yang dahulu dianggap minor, saat ini telah menimbulkan masalah yang serius diperkebunan kelapa sawit.

Pentingnya pengendalian hama UPDKS dalam kelapa sawit karena salah satu musuh yang sangat ditakuti dalam perkebunan kelapa sawit karena ulat tersebut menimbulkan efek kerugian yang sangat besar terhadap tanaman kelapa sawit. untuk tanaman kelapa sawit. Hama UPDKS menyerang bagian daun kelapa sawit, 
serangan hama UPDKS akan berdampak jangka panjang akan mempengaruhi kualitas dan kuantitas produksi di waktu mendatang.

Salah satu ancaman terhadap keberlangsungan usaha perkebunan kelapa sawit adalah serangan OPT yang dapat mempengaruhi kualitas, produksi, dan produktivitas kelapa sawit adalah ulat api. Serangan ulat api pada tanaman kelapa sawit dapat berpengaruh pada penurunan produksi. Prawirosukarto (2002) menyebutkan bahwa kerusakan daun yang ditimbulkan oleh ulat api terhadap tanaman yang menghasilkan (TM) berumur 8 tahun dapat menurunkan produksi hingga $30-40 \%$ setelah 2 tahun terjadinya serangan.

\section{METODE PENELITIAN}

\section{Tempat dan Waktu}

Penelitian ini dilaksanakan di pabrik PT. Farinda Bersaudara, Desa Jambuk, Kecamatan Bongan, Kabupaten Kutai Barat. Waktu penelitian ini dilaksanakan pada bulan Oktober hingga November 2020.

\section{Alat dan Bahan}

Alat yang di gunakan dalam penelitian ini adalah terdiri dari alat tulis, leptop, hendphone (untuk merekam suara dan dokumentasi) , Bahan yang di gunakan dalam penelitian ini adalah data primer dan sekunder.

\section{Metode Pengumpulan Data}

Observasi adalah proses pencatatan pola perilaku subjek (orang),objek (benda) atau kejadian sistematik tanpa adanya pertanyaan atau komunikasi dengan individuindividu yang diteliti (Indriantoro \& Supomo,1999:157). Dalam hal ini peneliti melakukan pengamatan langsung pada Koperasi Plasma Mekar Sejahtera mengenai bagaimana pengaruhnya koperasi Mekar Sejahtera terhadap anggotanya atau petani plasma.

Dokumentasi merupakan teknik pengumpulan data melalui arsip atau catatan yang terdapat pada perusahaan, Data-data tersebut berupa laporan pengendalian hama UPDKS.

\section{Prosedur Penelitian \\ Observasi melakukan pengamatan langsung kelapangan berupa kegiatan-}

kegiatan yang dilakukan oleh asisten maupun karyawan saat melakukan pengendalian.

Peninjauan lapangan

Peninjauan lapangan meliputi kegiatan penentuan lokasi yang akan di jadikan bahan penelitian maupun gambar untuk keperluan skripsi.

Dokumentasi yaitu memfoto kegiatan-kegiatan yang ada di lapangan pada saat pengendalian ataupun melakukan pengamatan dan pencatatan objek yang diteliti.

\section{Analisis Data}

Stelah smua data terkumpul dengan baik yang telah diperoleh dengan baik yang telah diperoleh dari lapangan baik lewat observasi, maupun dokumentasi maka selanjutnya adalah memberikan penganalisaan yang penulis lakukan menggunakan deskriptif kualitatif yang menghimpun data-data faktual dan mendeskripsikannya, deskripstif kualitatif juga mendeskripsikan gejala-gejala yang diteliti dalam bentuk kalimat atau kata-kata bukan dalam bentuk angka.

\section{HASIL DAN PEMBAHASAN}

\section{Gambaran Umum PT. Farinda}

TSH Group merupakan perusahaan Malaysia yang bergerak dalam bidang usaha termasuk perkebunan dan pabrik kelapa sawit. TSH Group selalu berusaha mematuhi peraturan yang dibuat pemerintah maupun oleh internasional dan memenuhi kepuasan pelanggan dengan memberikan pelayanan yang terbaik dan sesuai dengan persyaratan yang telah ditentukan ataupun ikatan kontrak yang dibuat bersama. Pada tahun 2005, Malaysia dan Indonesia melakukan kerja sama dibidang perkebunan kelapa sawit, tepatnya di Kabupaten Kutai Barat Provinsi Kalimantan Timur berdirilah perusahaan yang bernama PT. Farinda Bersaudara, Awal pembukaan lahan pada tahun 2007 dan memiliki tiga bagian estet, dimana estet itu ialah, estet Jambuk dengan luasan $8000 \mathrm{Ha}$, estet Siram Jaya dengan Iuasan $4000 \mathrm{Ha}$, dan estet Penawai dengan luasan kebun kelapa sawit $3000 \mathrm{Ha}$. Setiap estet memiliki luasan dan kondisi topografi yang berbedabeda.

PT. Farinda Bersaudara telah memiliki pabrik pengelolahan kelapa sawit sendiri 
dengan kapasitas pabrik 60 Ton/hari. Lokasi pabrik sendiri terdapat di estet Jambuk kecamatan Bongan Kabupaten Kutai Barat, dimana semua TBS yang terdapat di estet Siran Jaya, Penawai, kebun masyarakat, dan bahkan PT atau perusahaan lainnya yang berada dekat di wilaya PT. Farinda Bersaudara akan menghantar TBS mereka ke pabrik yang ada di estet Jambuk milik PT. Farinda Bersaudara tersebut.

Tabel 1. Data produksi sebelum dilakukannya pengendalian hama ulat pemakan daun (UPDKS)

\begin{tabular}{lc}
\hline \multicolumn{1}{c}{ Bulan } & Tahun 2019 \\
\hline Januari & $110 \%$ \\
Februari & $91 \%$ \\
Maret & $88 \%$ \\
April & $91 \%$ \\
Mei & $118 \%$ \\
Juni & $66 \%$ \\
Juli & $62 \%$ \\
Agustus & $73 \%$ \\
September & $90 \%$ \\
Oktober & $100 \%$ \\
November & $90 \%$ \\
Desember & $84 \%$ \\
\hline \multicolumn{1}{c}{ Total } & $88 \%$ \\
\hline
\end{tabular}

\section{Sensus Pokok Sawit}

\section{Perencanaan Sensus}

Definisi sensus adalah untuk menemukan kendala hama UPDKS sedini mungkin perlu dilakukan pemeriksaan rutin perkebunan kelapa sawit. Tujuan sensus yaitu untuk mengetahui seberapa besar gejala yang ditimbulkan hama UPDKS pada blok dan akan dilakukan pengendalian apabila melewati ambang batas ekonomi. Manfaat sensus adalah untuk mengurangi dampak hama UPDKS di perkebunan kelapa sawit dan mengetahui seberapa banyak populasi hama yang ada di blok tersebut.

Asisten dan mandor mempersiapkan rencana kerja sebelum melakukan kegiatan sensus yaitu menentukan blok yang akan di sensus dan melakukan sensus dengan mengecek semua pokok kelapa sawit. Jumlah karyawan sensus 6 orang dengan target 6 hari dan target 2 orang /blok menyiapkan kan alat dan bahan, alat tulis dan buku untuk mencatat pokok yang terkena serangan baru hama ulat pemakan daun kelapa sawit (UPDKS).

Sensus dilakukan pada bulan 10 dengan jumlah blok yang akan di sensus adalah 18 blok dengan tahun tanam 2008 dan 2009. Ambang batas ekonomi hama UPDKS yaitu $>5 \%$ maka akan dilakukan pengendalian dan jika $<5 \%$ ambang batas ekonomi maka tidak dilakukan pengendalian.

\section{Pengorganisasian}

1) Asisten bertanggung jawab dalam kegiatan sensus, mulai dari kegiatan brefing pagi, pengawasan di lapangan hingga pemerikasaan hasil sensus

2) Mandor bertanggung jawab untuk mengarahkan karyawan sensus sesuai dengan jalur sensus yang benar, sehingga tidak terjadi kesalahan dalam kegiatan sensus.

3) Karyawan sensus berjumlah 6 orang bertanggung jawab dengan blok yang di sensus, harus sesuai dengan standar operasional perusahaan (SOP).

\section{Pelaksanaan Sensus}

Pelaksanaan kegiatan dilakukan dengan jumlah 6 orang karyawan dengan target 2 orang/blok, dengan waktu sensus selama 6 hari, mengecek semua pokok kelapa sawit, dengan menggunakan alat tulis dan buku blok yang telah tersensus adalah blok:

\begin{tabular}{|c|c|c|}
\hline $\begin{array}{l}\text { 1). E13 luas } \\
24 \text { ha }\end{array}$ & $\begin{array}{l}\text { 7). E19 luas } \\
=25 \text { ha }\end{array}$ & $\begin{array}{l}\text { 13). D15 luas } \\
=8 \mathrm{ha}\end{array}$ \\
\hline $\begin{array}{l}\text { 2). E14 luas } \\
25 \text { ha }\end{array}$ & $\begin{array}{l}\text { 8). E20 luas } \\
=26 \mathrm{ha}\end{array}$ & $\begin{array}{l}\text { 14). D16 luas } \\
=8 \mathrm{ha}\end{array}$ \\
\hline $\begin{array}{l}\text { 3). E15 luas } \\
23 \text { ha }\end{array}$ & $\begin{array}{l}\text { 9). E21 luas } \\
=8 \mathrm{ha}\end{array}$ & $\begin{array}{l}\text { 15). D17 luas } \\
=8 \mathrm{ha}\end{array}$ \\
\hline $\begin{array}{l}\text { 4). E16 luas } \\
24 \text { ha }\end{array}$ & $\begin{array}{l}\text { 10). E22 lua } \\
=15 \text { ha }\end{array}$ & $\begin{array}{l}\text { 16). D18 luas } \\
=15 \text { ha }\end{array}$ \\
\hline $\begin{array}{l}\text { 5). E17 luas } \\
25 \text { ha }\end{array}$ & $\begin{array}{l}\text { 11). D13 luas } \\
=23 \mathrm{ha}\end{array}$ & $\begin{array}{l}\text { 17). D19 luas } \\
=8 \mathrm{ha}\end{array}$ \\
\hline $\begin{array}{l}\text { 6). E18 } \\
24 \text { ha }\end{array}$ & $\begin{array}{l}\text { 12). D1 } \\
=8 \mathrm{ha}\end{array}$ & $\begin{array}{l}\text { 18). D20 } \\
=15 \mathrm{ha}\end{array}$ \\
\hline
\end{tabular}


Mengecek semua dari awal hingga akhir blok, melihat pelepah apakah ada serangan baru yaitu daun berlubang menyisakan lidi saja, dan apabila ada 1 pelepah yang terserang dan terhitung satu serangan hama ulat pemakan daun (UPDKS).

Dari hasil sensus yang telah dilakukan selama 6 hari yang dilakukan oleh 6 orang telah mencapai target yang telah direncanakan (Tabel 2)

Dari hasil sensus yang telah dilakukan, blok yang terserang hama di atas ambang batas ekonomi yaitu $>5 \%$ dan harus dilakukan pengendalian hama (Tabel 3).
Tabel 2. Target sensus hama ulat pemakan daun kelapa sawit (UPDKS)

\begin{tabular}{cccc}
\hline Hari & $\begin{array}{c}\text { Jumlah } \\
\text { TK }\end{array}$ & Target & $\begin{array}{c}\text { Hasil Blok } \\
\text { Yang } \\
\text { Tersensus }\end{array}$ \\
\hline 1 & 6 & 3 blok & 3 blok \\
2 & 6 & 3 blok & 3 Blok \\
3 & 6 & 3 blok & 3 Blok \\
4 & 6 & 3 blok & 3 Blok \\
5 & 6 & 3 blok & 3 Blok \\
6 & 6 & 3 blok & 3 Blok \\
\hline & & & Total 18 \\
& & & Blok \\
\hline
\end{tabular}

Tabel 3. Hasil sensus Hama ulat Pemakan Daun kelapa sawit (UPDKS)

\begin{tabular}{lccccc}
\hline Blok & Ha & Jumlah Pokok & $\begin{array}{c}\text { Jumlah Pokok } \\
\text { trserang }\end{array}$ & $\begin{array}{c}\text { Jenis Hama } \\
\text { updks }\end{array}$ & $\begin{array}{c}\text { Ambang batas } \\
\text { ekonomi }\end{array}$ \\
\hline E13 & 24 & 3.145 & 372 & Darna trima & $11,82 \%$ \\
E14 & 25 & 3.237 & 122 & Darna trima & $3,72 \%$ \\
E15 & 23 & 3.139 & 134 & Darna trima & $4,26 \%$ \\
E16 & 24 & 3.267 & 141 & Darna trima & $4,31 \%$ \\
E17 & 25 & 3.430 & 162 & Darna trima & $4,72 \%$ \\
E18 & 24 & 3.213 & 150 & Darna trima & $4,66 \%$ \\
E19 & 25 & 3.230 & 104 & Darna trima & $3,21 \%$ \\
E20 & 26 & 3.360 & 351 & Darna trima & $10,44 \%$ \\
E21 & 8 & 1.228 & 52 & Darna trima & $4,23 \%$ \\
E22 & 15 & 2.070 & 102 & Darna trima & $4,92 \%$ \\
D13 & 23 & 3.006 & 137 & Darna trima & $4,55 \%$ \\
D14 & 8 & 1.122 & 41 & Darna trima & $3,65 \%$ \\
D15 & 8 & 1.214 & 60 & Darna trima & $4,94 \%$ \\
D16 & 8 & 1.176 & 29 & Darna trima & $2,46 \%$ \\
D17 & 8 & 1.228 & 48 & Darna trima & $3,90 \%$ \\
D18 & 15 & 2.070 & 301 & Darna trima & $14,54 \%$ \\
D19 & 8 & 1.228 & 32 & Darna trima & $2,60 \%$ \\
D20 & 15 & 2.070 & 98 & Darna trima & $4,73 \%$ \\
\hline & & & & & \\
\hline
\end{tabular}




\section{a. Pengawasan}

Pengawasan dilakukan oleh asisten dan mandor pada saat kegiatan sensus berlangsung agar karyawan tidak melewati pokok yang belum tersensus dengan benar. Setelah pekerjaan sudah selesai, mandor mencatat hasil kerja karyawan ke dalam buku laporan harian mandor (LHM). Pencatatan hasil kerja karyawan ini dilakukan disore hari atau setelah pekerjaan selesai.

\section{b. Evaluasi}

Sensus hama ulat pemakan daun kelapa sawit (UPDKS) di PT. Farinda Bersaudara Estate penawai telah sesuai Standar Operasional Perusahaan (SOP) yaitu dengan mensensus seua pokok dan mencatat serangan baru apabila terdapat 1 pelepah hanya menyisakan lidi akibat serangan hama ulat pemakan daun kelapa sawit (UPDKS).

\section{c. Perbaikan}

Perbaikan dilakukan setelah hasil dilakukannya evaluasi. Perbaikan akan dilaksanakan semaksimal mungkin agar mendapatkan hasil yang memuaskan serta target yang telah ditentukan dapat tercapai.

\section{Prosedur pengendalian}

a. Perencanaan pengendalian hama UPDKS Asisten dan mandor mempersiapkan rencana kerja untuk mengarah kan para karyawan sebelum pengendalian dilaksanakan, karyawan pengendalian hama berjumlah 27 orang dan dibagi menjadi 9 tim. 1 tim berjumlah 3 orang, 1 laki-laki dan 2 perempuan.

Jumlah pokok yang akan dilakukan pengendalian adalah 1024 pokok kelapa sawit, dengan 2 lubang /pokok kelapa sawit. 1 laki-laki bertugas untuk mengoperasikan alat bor dan mengebor 2 lubang per pokok dan 1 perempuan untuk menyuntikan larutan achephate kedalam lubang dengan kecepatan $10 \mathrm{ml} /$ lubang, 1 perempuan lagi untuk menyiapkan tanah liat untuk lubang segel dan untuk menutup lubang setelah injeksi larutan achepate, untuk memastikan semua lubang di tutup dengan benar.

Tabel 4. Kawasan/blok pengendalian hama UPDKS

\begin{tabular}{cccccc}
\hline Blok & Ha & Pokok & $\begin{array}{c}\text { Pokok } \\
\text { Terserang }\end{array}$ & Jenis Hama & $\begin{array}{c}\text { Ambang batas } \\
\text { ekonomi }\end{array}$ \\
\hline E13 & 24 & 3.145 & 372 & Darna trima & $11,82 \%$ \\
E20 & 26 & 3.360 & 351 & Darna trima & $10,44 \%$ \\
D18 & 15 & 2.070 & 301 & Darna trima & $14,54 \%$ \\
\hline
\end{tabular}

b. Pengorganisasian

1) Asisten bertanggung jawab dalam kegiatan pengendalian, mulai dari kegiatan brefing pagi, pengawasan di lapangan hingga pemeriksaan hasil kerja dibuku laporan harian mandor (LHM).

2) Mandor bertugas untuk apel pagi bersama dengan karyawan penyemprotan, yang dimulai dari jam 06.00 pagi, mengabsen karyawan, memberikan arahan kepada karyawan tentang pekerjaan yang dilakukan, kemudian memonitor, mengawas dan mencatat hasil kerja karyawan di buku laporan harian mandor (LHM)yang diisi oleh mandor.

3) Karyawan untuk pengendalian UPDKS berjumlah 27 karyawan dan dibagi menjadi 9 tim dengan 1 tim berjumalah 3 orang. Melaksanakan kegiatan pengendalian sesuai perintah dari asisten, terlebih dahulu mengecek semua alat dan bahan yang ada sebelum menuju ke blok yang akan dilakukan pengendalian.

c. Pelaksanaan pengendalian

Melaksanakan kegiatan pengendalian sesuai perintah dari asisten, terlebih dahulu mengecek semua alat dan bahan yang ada sebelum menuju ke blok yang akan dilakukan pengendalian, pelaksanaan dilakukan pada pagi hari pukul 8:00 stelah brefing pagi dan mempersiapkan alat dan bahan yaitu;

1) Alat
a) Bor mesin
b) Suntik
c) Selang kecil
d) Ember

2) Bahan
a) Racun achepate
b) Air
c) Tanah liat 
Standar Operasional Perusahaan (SOP) di PT. Farinda Bersaudara Pengendalian hama ulat pemakan daun kepala sawit (UPDKS) dengan menggunakan injeksi batang atau dengan menyuntikan bahan racun ke pokok kelapa sawit yang terserang. Yaitu mengobor 2 lubang pada $30 \mathrm{~cm}$ tinggi pokok, satu lubang diisi achepate $=4,0 \mathrm{gm}$ dengan 1 pokok berisi acephate $8,0 \mathrm{gm}$. 1 pokok berisi $20 \mathrm{ml}$ air, dengan 1 lubang berisi $10 \mathrm{ml}$ dan menutup lubang menggunakan tanah liat.

Dari hasil pengendalian Hama Ulat Pemakan Daun Kelapa sawit (UPDKS) yang dilakukan oleh 27 karyawan selama 6 hari jumlah pokok terserang 1024 adalah.

Tabel 5. Hasil Pengendalian hama UPDKS

\begin{tabular}{cccccc}
\hline No & Waktu s/d & $\begin{array}{c}\text { pokok } \\
\text { Terserang }\end{array}$ & Jumlah racun & air & Ket \\
\hline 1 & $08.00-02.00$ & 170 & $1,36 \mathrm{~kg}$ larutan achepate & $3,400 \mathrm{~L}$ & baik \\
2 & $08.00-02.00$ & 170 & $1,36 \mathrm{~kg}$ larutan achepate & $3,400 \mathrm{~L}$ & baik \\
3 & $08.00-02.00$ & 169 & $1,35 \mathrm{~kg}$ larutan achepate & $3,380 \mathrm{~L}$ & baik \\
4 & $08.00-02.30$ & 173 & $1,38 \mathrm{~kg}$ larutan achepate & $3,460 \mathrm{~L}$ & baik \\
5 & $08.00-02.00$ & 165 & $1,32 \mathrm{~kg}$ larutan achepate & $3,300 \mathrm{~L}$ & baik \\
6 & $08.00-03.00$ & 177 & $1,41 \mathrm{~kg}$ larutan achepate & $3,540 \mathrm{~L}$ & baik \\
\hline & Total & 1024 Pokok & 8,18 kg Larutan & $20,48 \mathrm{~L}$ & baik \\
\hline
\end{tabular}

Tabel 6. Data produksi setelah dilakukannya pengendalian hama ulat Pemakan daun kelapa sawit (UPDKS) adalah

\begin{tabular}{lc}
\hline \multicolumn{1}{c}{ BULAN } & Tahun 2020 \\
\hline Januari & $89 \%$ \\
Februari & $70 \%$ \\
Maret & $73 \%$ \\
April & $65 \%$ \\
Mei & $72 \%$ \\
Juni & $76 \%$ \\
Juli & $112 \%$ \\
Agustus & $94 \%$ \\
September & $116 \%$ \\
Oktober & $112 \%$ \\
November & $102 \%$ \\
desember & $128 \%$ \\
\hline \multicolumn{1}{c}{ TOTAL } & $92 \%$ \\
\hline
\end{tabular}

Setelah dilakukannya pengendalian, pengecekan hasil kembali selama 40 hari, dan apabila tidak terdapat penurunan atau pokok yang terserang tidak membaik maka dilakukan recensus ulang. Dari hasil pengendalian selama 6 hari dengan jumlah pokok terserang 1024 dengan jumlah larutan racun achepate $8,18 \mathrm{~kg}$ dan jumlah air 20,48 liter dinyatakan membaik setelah di observasi di lapangan

\section{d. Pengawasan}

Asisten dan mandor mengecek kembali di lapangan hasil dari kualitas kerja karyawan, apakah sudah sesuai dengan arahan yang diberikan oleh mandor/asisten atau tidak. Teknik pengawasan yaitu melakukan pengawasan diareal yang akan dilakukan pengendalian, mengawasi kegiatan pengendalian dan memantau kualitas dan kuantitas pekerjaan karyawan sesuai dengan SOP perusahaan.

Mandor melakukan pengawasan dari pagi hari sampai dengan pekerjaan pengendalian selesai dilakukan. Ini dilakukan agar tidak ada pekerjaan pengendalian yang tidak sesuai dengan SOP. Sebab apabila kurang pengawasan biasanya banyak karyawan yang sengaja boros menggunakan racun agar target mereka cepat selesai.

e. Evaluasi

Dari hasil pengendalian hama ulat pemakan daun kelapa sawit (UPDKS) di PT. 
Farinda Bersudara estate Penawai telah sesuai dengan standar operasional perusahaan (SOP) dengan menggunakan metode injeksi batang dengan menyuntikan larutan achepate 2 lubang $=8 \mathrm{gr} /$ kelapa sawit dan $20 \mathrm{ml} /$ kelapa sawit.

\section{f. Perbaikan}

Perbaikan dilakukan setelah hasil dilakukannya evaluasi. Perbaikan akan dilaksanakan semaksimal mungkin agar mendapatkan hasil yang memuaskan serta target yang telah ditentukan dapat tercapai.

\section{KESIMPULAN}

Manajemen pengendalian ulat api dan ulat daun secara kimiawi. Di PT. farinda Bersaudara dimulai dari perencananan, pengorganisasian, pelaksanaan, pengawasan, perbaikan.

Manajemen dalam melakukan pengendalian terhadap gejala dan kerusakan yang ditimbulkan hama ulat pemakan daun kelapa sawit (UPDKS) di PT. Farinda Bersaudara efektif sekitar $90 \%$. Dan meningkat hasil produksi sebesar $4 \%$ dilihat dari data produksi tahun 2019 yaiut $88 \%$ dan setelah dilakukannya pengendlian data produksi tahun 2020 menjadi $92 \%$.

\section{DAFTAR PUSTAKA}

Anonim. Kriteria Serangan Hama Ulat Api Sethotosea asigna. Pusat Penelitian Kelapa Sawit. Medan.

Gunawan, W.E. 2012. Kajian Biaya Pengendalian Hama Ulat Api Pada Tanaman Kelapa Sawit (Elaeis Guineensis Jacq) di Perkebunan Nusantara IV Adolina. Tugas Akhir Program Budidaya Perkebunan. STIPAP Medan).

Hartley.1979.Siklus Hidup Ulat api (EWS). Pusat Penelitian Kelapa Sawit (PPKS).

Hidayat, Wahyu. 2013. Kajian Biaya Ulat Api. Kebun Kelapa Sawit Gunung Bayu. PTPN IV.

Lubis, R.E.dan A. Widanarko. 2011. Buku Pintar Kelapa Sawit. Agromedia. Jakarta Selatan

Pahan dan Gunawan. 1997. Metodologi Pengendalian Hama Ulat Pemakan Daun Kelapa Sawit (UPDKS).
Parinduri,S. 2011. Pengendalian Hama dan Penyakit Tanaman Kelapa Sawit. Bahan Ajar Sekolah Tinggi Ilmu Pertanian Agribisnis Perkebunan Medan.

Soepedio,M. 2008. Manajemen Agrobisnis Kelapa Sawit. Gadjah Mada University prees. Jakarta.

Wawan, P. Pedoman Teknis Hama Dan Penyakit Pada Tanaman Kelapa Sawit. http://www.wordpress.com. Diakses tanggal 24 November 2013. 